\title{
A Psicologia no Modelo Atual de Atenção em Saúde Mental
}

Pychology In The Current Model Of Mental Health

La Psicología En El Modelo Actual

De Atención En Salud Mental
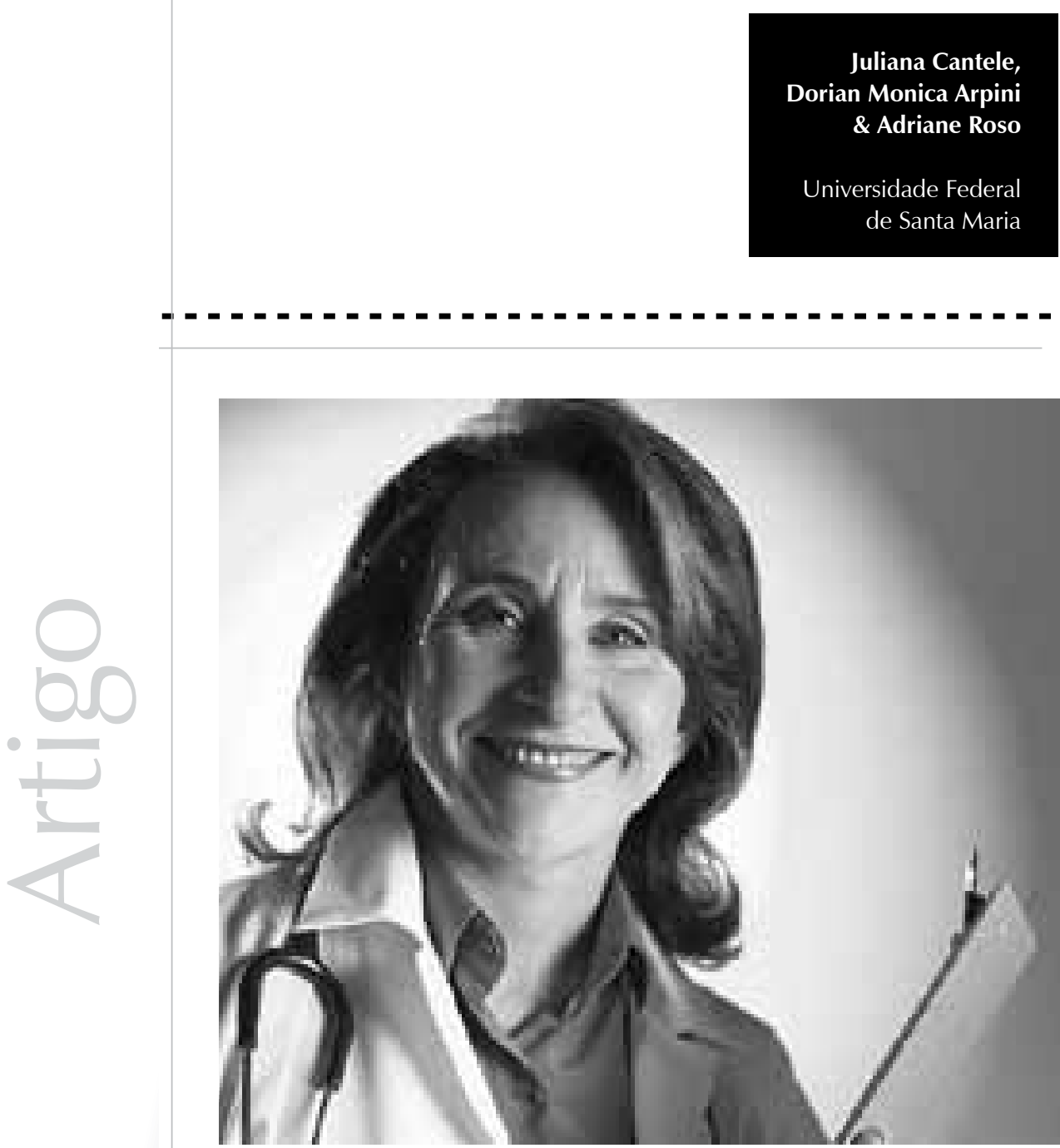
Resumo: O presente estudo teve como objetivo conhecer a experiência dos profissionais da Psicologia dentro do atual modelo de atenção em saúde mental. Foi realizado um estudo qualitativo, com a utilização da técnica de entrevistas semiestruturadas, tendo como participantes sete psicólogos de três Centros de Atenção Psicossocial de uma cidade de porte médio do Rio Grande do Sul. Os resultados foram analisados através da análise de conteúdo, e revelaram o impacto inicial vivenciado pelos profissionais, manifestado através dos sentimentos de medo, frustração e impotência. Os participantes evidenciaram a importância de um constante repensar da ação profissional, destacando a realização de capacitação quando da entrada do profissional no serviço e da supervisão clínico-institucional como recurso para qualificar a prática, e ressaltaram a importância de um trabalho em equipe e do olhar multiprofissional em relação ao usuário. Pode-se concluir que os profissionais da Psicologia têm um papel preponderante nas equipes que compõem os CAPS.

Palavras-chave: Saúde. Psicologia da saúde. Centro de Atenção Psicossocial. Serviços de saúde mental.

Abstract: This study had as aim to know the experience of psychology professionals considering the current mental health care model. A qualitative study was carried out, using semi-structured interviews. The participants were seven psychologists of three Psychosocial Assistance Centers of a medium-sized city of Rio Grande do Sul. The results were analyzed through content analysis, and revealed the initial impact experienced by the professionals expressed through feelings of fear, frustration and powerlessness. The participants highlighted the importance of constant reflection on their professional actions, emphasizing the training when beginning to integrate service and clinical and institutional supervision as a resource to qualify the practice. They focused on the importance of a team work and the multiprofessional perspective related to the user. Thus, it is possible to conclude that psychology professionals have a preponderant role concerning the current model of mental health care in the country.

Keywords: Health. Health psychology. Psychosocial Assistance Centre. Mental health services.

Resumen: El presente estudio tuvo como objetivo conocer la experiencia de los profesionales de la Psicología dentro del actual modelo de atención en salud mental. Fue realizado un estudio cualitativo, con la utilización de la técnica de entrevistas semiestructuradas, teniendo como participantes siete psicólogos de tres Centros de Atención Psicosocial de una ciudad de mediano porte de Rio Grande do Sul. Los resultados fueron analizados a través del análisis de contenido, y revelaron el impacto inicial vivido por los profesionales, manifestado a través de los sentimientos de miedo, frustración e imposibilidad. Los participantes evidenciaron la importancia de un constante repensar de la acción profesional, destacando la realización de capacitaciones en el momento de la entrada del profesional en el servicio y de la supervisión clínicoinstitucional como recurso para calificar la práctica, y resaltaron la importancia de un trabajo en equipo y de la visión multiprofesional con relación al usuario. Se puede concluir que los profesionales de la Psicología tienen un papel preponderante en los equipos que componen los CAPS.

Palabras clave: Salud. Psicología de la salud. Centro de Atención Psicosocial. Servicios de salud mental.

Alguns dos espaços de atuação do psicólogo brasileiro têm sido os Centros de Atenção Psicossocial (CAPS), que compõem uma rede interligada que se origina da política da reforma psiquiátrica. Considera-se, então, que uma das funções desse dispositivo é a de cuidar dos pacientes de maneira mais humanitária, abordando a saúde e a cidadania como um direito de todos os sujeitos com algum sofrimento (Cunha \& Maciel, 2008).

\section{Os Centros de Atenção Psicossocial}

... são serviços de saúde municipais, abertos, comunitários, que oferecem atendimento diário às pessoas com transtornos mentais severos e persistentes, realizando o acompanhamento clínico e a reinserção social dessas pessoas através do acesso ao trabalho, lazer, exercício dos direitos civis e fortalecimento dos laços familiares e comunitários (Brasil, 2005, p. 27)

É função dos CAPS prestar atendimento clínico em regime de atenção diária, evitando assim as internações em hospitais psiquiátricos, promover a inserção social das pessoas com transtornos mentais através de ações intersetoriais, regular a porta de entrada da rede de assistência em saúde mental na sua área de atuação e dar suporte à atenção à saúde mental na rede básica, ou seja, os CAPS têm o dever de organizar a 
rede de atenção às pessoas com transtornos mentais nos Municípios (Brasil, 2005).

Desse modo, os CAPS devem ser substitutivos ao modelo hospitalocêntrico, promovendo a inserção social e garantindo os direitos de cidadania desses pacientes. Ao mesmo tempo, o tratamento extra-hospitalar contribui para a reabilitação social dos portadores de sofrimentos mentais, buscando incluir em seu campo de intervenções a esfera do trabalho, a do Direito, a da moradia, a do lazer e a da cultura. Incide ainda, nesses serviços, o fortalecimento dos laços familiares e comunitários através do convívio social (Brasil, 2005). Os CAPS se distinguem por sua complexidade e organizam-se de acordo com o número populacional de cada cidade. Com isso, esses serviços se caracterizam como: CAPS I, CAPS II, CAPS III, CAPSi e CAPSad (Brasil, 2002).

Dentre os profissionais que se inserem no serviço, encontramos o psicólogo. Sabemos que a inserção do psicólogo na saúde pública brasileira se deu em consequência das mudanças ocorridas na sociedade brasileira em geral, principalmente na área da saúde. Por um lado, destacava-se a crise econômica e social, que afastava os pacientes dos consultórios privados, “... forçando os psicólogos a buscarem outros contextos de atuação" (Goya \& Rasera, 2007, p.1). Por outro lado, as políticas de atenção em saúde mental geraram a "... ambulatorização dos serviços e a multiprofissionalidade na atenção dos portadores de sofrimento psíquico".

Lima cita alguns fatores que foram importantes para a entrada do psicólogo nos serviços públicos de saúde:

a) o contexto das políticas públicas de saúde no final dos anos de 1970 e em toda a década de 1980, particularmente a repercussão no setor de recursos humanos, b) a diminuição de busca aos consultórios de Psicologia por parte da população, causada por seu empobrecimento, a partir dos anos 80, c) o movimento da própria categoria com o objetivo de redefinir a função social da Psicologia na sociedade e d) a difusão da psicanálise e a psicologização da sociedade (2005, p. 431)

Dessa forma, nota-se que a Psicologia passa por duas principais crises, pelas quais o campo e a formalização de um novo paradigma de práticas profissionais são repensados em relação à prática desenvolvida até então. A primeira crise se consolidou com a prática clínica tradicional que provém do modelo médico hegemônico existente na época, em consequência, restrita em função dos aspectos econômicos e socioculturais de um determinado grupo. Já a segunda crise vai se constituir por meio das instituições psiquiátricas e de sua maneira desumana de lidar com a loucura.

Neto aponta diversos estudos que se referem ao aumento da inserção dos psicólogos na saúde pública no Brasil, decorrentes da reforma psiquiátrica e da criação do campo de atuação denominado saúde mental. Além disso, destaca a preocupação relativa à integração entre saúde mental e os contextos mais gerais de saúde, bem como o envolvimento dos profissionais em ações coletivas:

... é marcante a preocupação da integração da saúde mental no contexto geral da saúde e a participação de seus profissionais em ações coletivas com outros profissionais do serviço. As práticas de grupo se constituem numa importante diretriz de trabalho, tendo nos psicólogos um de seus principais agentes (Neto, 2008, p. 21)

A significativa guinada, no que diz respeito à inserção dos psicólogos na saúde, ocorreu após a década de 80 , com a implantação de uma política específica de desinstitucionalização e da ampliação da rede de serviços substitutivos de saúde mental, como afirma Spink (2003), além de considerar a construção da Psicologia 
da saúde um campo de saber inserido em equipes de saúde mental integradas por um psiquiatra e um assistente social, dentre outros, constituindo, assim, uma organização nos serviços agregados aos níveis primário, secundário e terciário. A composição dessas equipes multiprofissionais não foi uma tarefa simples. De um lado, deu-se a resistência por parte de outros profissionais que não entendiam a função conferida aos membros dessas equipes; por outro lado, esses novos profissionais careciam de alicerces teóricos - práticas imprescindíveis para a construção dessa nova concepção de serviço, que se desviava dos parâmetros tradicionais de atuação dos profissionais que historicamente os integraram.

Primeiramente, na Psicologia, encontramos as carências de uma formação baseada em um modelo clínico privado de consultório, que não é suficiente para a prioridade do programa em questão (Oliveira et al., 2004; Lima, 2005). No entanto, com a entrada dos psicólogos no Sistema Único de Saúde (SUS), a compreensão de clínica vem sendo renovada pelas novas perspectivas agora denominadas clínica ampliada (Neto, 2008). Nessa nova proposta de atenção em saúde mental, o trabalho em equipes multiprofissionais passa a ser uma prioridade. O psicólogo, então, ao lado de outros profissionais, passa a integrar o novo modelo de atenção. De acordo com a VIII Conferência Nacional de Saúde (Brasil, 1986), deu-se início a uma movimentação, tanto da Psicologia quanto das outras profissões envolvidas na saúde, no sentido da ampliação das ações para além dos ambulatórios e hospitais.

Inicialmente, alguns psicólogos acabavam trabalhando de forma isolada, adotando uma postura médica, desconsiderando outras dimensões, entre elas, a própria prática médica, como pontua Spink (2003). Geralmente, sua participação na equipe era a de facilitador do tratamento, em que tinham precárias oportunidades de colaborar como profissionais autônomos.

A partir desse novo campo de trabalho que se apresentava ao psicólogo, surgiram vários questionamentos referentes à sua formação e à sua capacitação para ampliar suas atividades nesse espaço, o que demandaria um repensar em torno da saúde e da doença e seus diversos aspectos - políticos, sociais, econômicos e psicológicos. Com a presente demanda de psicólogos, fez-se necessária a procura pela definição do campo, do lugar e especialmente das aptidões, conhecimentos e habilidades que devem compor o currículo para a formação desses profissionais.

Kubo e Botomé identificam diversas atribuições do psicólogo, dentre elas,

a preparação do doente mental para sua reinserção social e sua manutenção na comunidade, a orientação da família dos pacientes, a preparação e orientação profissional do doente mental, a realização de pesquisas e avaliação de programas, a participação na formação dos demais trabalhadores de saúde mental e a produção de informação à sociedade sobre aspectos relacionados à saúde mental. (2001, p. 4)

A essas especificas atribuições da Psicologia, junta-se ainda outra maior, que percorre a prática de todos os profissionais incluídos na saúde mental empenhados com o movimento antimanicomial: "... a de criar um conjunto amplo de medidas que interfiram nas condições de vida do paciente e permitam criar alianças e vínculos fortes com a comunidade" (Kubo \& Botomé, 2001, p. 4). Segundo os autores, é plausível dizer, mesmo considerando a disposição geral do trabalho do psicólogo no campo da saúde mental, que algumas dificuldades estão sendo superadas e que a ligação dos profissionais da equipe dá abertura para tornar essa disposição percebível.

De acordo com Pietroluongo e Resende, o psicólogo, devido a sua formação diferenciada, 
Para Fagundes,

"... a Psicologia tem um potencial

transversalizador das práticas sociais e institucionais..." (2004, p. 4), tem um lugar essencial dentro da equipe multidisciplinar, lugar que se constrói a partir da escuta, que possibilita que o profissional desenvolva momentos de subjetivação no âmbito familiar, ampliando a percepção da equipe e da família em torno dos problemas levantados por esta. De acordo com os autores, por "... conhecer os processos relacionais, o psicólogo pode ajudar a compreender, dentro de um espaço social, que lugares estão sendo construídos para os sujeitos (equipe, usuários e família) e de que forma podem-se construir novas relações para que esses lugares sejam condizentes com os pressupostos da reforma (2007, p. 7). Os autores também argumentam que é necessário ressaltar que qualquer membro da equipe está apto a estabelecer relações que beneficiem a organização familiar, caso contrário, o saber dominador apenas se deslocaria de uma especialidade para outra, ou seja, deixaria de pertencer à psiquiatria e passaria a pertencer à Psicologia, como pontuam os autores. O principal pressuposto da reforma psiquiátrica é a desconstrução do estigma da loucura como doença orgânica, que passa a ser vista em sua complexidade; dessa forma, não faz o menor sentido estabelecer outro poder soberano.

Desse modo, o grande desafio para todos os integrantes da equipe multiprofissional não é só conhecer a sua função mas também conseguir estimar e reconhecer o papel do outro como essencial para se obter uma visão complexa dos fenômenos. Assim, pode-se ter um grupo horizontalizado e não hierarquizado no qual apenas um detém o saber, possibilitando "... abertura à reflexão e a novas alternativas relacionais e de ação terapêutica" (Pietroluongo \& Resende, 2007, p. 8).

Para Fagundes, “... a Psicologia tem um potencial transversalizador das práticas sociais e institucionais..." (2004, p. 4), o qual tem contribuído cada vez mais para a invenção de maneiras de andar tanto na saúde coletiva quanto na desinstitucionalização da loucura. Ainda segundo a autora, os psicólogos são atores importantes na construção/invenção de políticas públicas no Brasil, em especial, na área da saúde, na formulação de novas propostas, na formação de profissionais, na produção de conhecimentos, na invenção da atenção, ao designar dispositivos clínicos e de cuidados, e na participação em conselhos de saúde, entre muitos outros.

O psicólogo é convocado a desenvolver estratégias para a adaptação “... de seu instrumental teórico-prático" (Brasil, 2004, p.185), viabilizando a reintegração e a ressocialização dos usuários por meio do cuidado contínuo. Faz-se indispensável "desenvolver abordagens participativas", nas quais o usuário, junto a seus familiares e à comunidade em geral, sejam reconhecidos como atores, cooperando com a gestão de políticas de saúde e motivando a geração de serviços descentralizados, flexíveis e apropriados aos interesses da clientela. Dessa forma, o profissional da Psicologia "... deve estar atento à avaliação de seus serviços e práticas no campo da saúde, pois, mediante o fornecimento de informações relevantes, pode fundamentar novas decisões, novas formas de atuar, possibilitando o aprimoramento da prestação de serviços" (Brasil, 2004, p.185).

Nessa perspectiva, são vários os movimentos em que os psicólogos, por meio de suas representações, têm sido convidados a participar, no intuito de dar entusiasmo aos processos de mobilização empenhados na ação da reforma psiquiátrica, batalha que define as demandas indispensáveis na reinvenção das práticas psi dentro do atual modelo de atenção à saúde (Nascimento, 2004).

Atualmente, vem sendo questionado o modelo de atendimento psicológico 
tradicional fornecido à população, sobreposto ao conjunto da saúde coletiva. Pensa-se que esse modelo de sessões individuais de extensa permanência com enquadre ortodoxo não tenha mais amparo. Entretanto, isso não quer dizer que tais práticas necessitam ser abolidas, mas sim, que "... novos modelos precisam ser pensados para dar conta da demanda atual" (Melo \& Borges, 2008, p. 4). Portanto, segundo os autores, “... vivenciamos exatamente um período de transição em que as reflexões e teorias estão em dissonância com as diversas práticas existentes" (Melo \& Borges, 2008, p. 5).

Contudo, considera-se de extrema importância a constituição e a concretização do lugar do psicólogo nos serviços públicos de saúde, possibilitando a abertura de novos espaços para se repensar a sua prática profissional na área da saúde mental, conhecendo os paradigmas que embasam suas práticas dentro dessas instituições e adequando um modelo assistencial que responda de fato às demandas dos usuários.

Nossa experiência no âmbito dos CAPS propiciou não somente o fortalecimento de modos de ação diferenciados mas também muitas dúvidas. Constantemente nos questionamos sobre qual seria, de fato, o lugar do psicólogo dentro desse novo modelo de atenção em saúde mental. Quais as dificuldades encontradas por esses profissionais uma vez que a história da prática da Psicologia sempre foi muito individual e fechada? Como nos preparar para enfrentar uma perspectiva de trabalho para a qual muitos de nós ainda nos sentimos inexperientes?

Em concordância com Barbosa (2004), acreditamos que o atual modelo de atendimento reacende novas discussões, e o nosso serviço é lidar com tais impasses da prática buscando incansavelmente a formação continuada, pois outros tipos de responsabilidades se instalam para que esses novos dispositivos possam desempenhar efetivamente seu papel.

Nesse sentido, a pesquisa aqui apresentada toma como pano de fundo esses questionamentos na tentativa de compreender como a Psicologia tem construído a sua inserção nesses territórios. Assim, tivemos como objetivo conhecer a experiência dos profissionais da Psicologia dentro do atual modelo de atenção em saúde mental em uma cidade de médio porte no interior do Estado do Rio Grande do Sul.

\section{Método}

Para a realização deste trabalho, elegeu-se a abordagem de caráter qualitativo, para melhor contribuição a fim de efetivar a presente pesquisa. Assim, acredita-se que "a finalidade real da pesquisa qualitativa não seja contar opiniões ou pessoas, mas ao contrário, explorar o espectro de opiniões, as diferentes representações sobre o assunto em questão" (Bauer \& Gaskell, 2005, p. 68).

Entende-se que o uso da técnica de entrevista individual semiestruturada seja frutífero nas abordagens qualitativas. Conforme Bauer e Gaskel, a pesquisa com entrevistas é um processo social de interação, de troca de ideias e de significados, em que várias realidades e percepções são exploradas e desenvolvidas. Com respeito a isso, tanto o(s) entrevistado(s) como o entrevistador estão, de maneiras diferentes, envolvidos na produção de conhecimento.

Participaram do estudo sete psicólogos inseridos em três instituições de saúde mental de uma cidade de médio porte localizada no Estado do Rio Grande do Sul (RS): foram entrevistados três psicólogos no CAPS infantil, dois no CAPS (Ad) e dois no CAPS II. Após a escolha dos locais para a realização das entrevistas e a aprovação do Comitê de Ética 
em Pesquisa (CAAE: 0127.0.243.000-09), os procedimentos da pesquisa tiveram início.

Seguimos a abordagem de entrevista proposta por Bauer e Gaskell, na qual: “... a entrevista começa com alguns comentários introdutórios sobre a pesquisa, uma palavra de agradecimento ao entrevistado por ter concordado em falar, e um pedido para gravar a sessão" (2005, p. 82). Também foi informado que seria necessário gravá-las em aúdio para futura transcrição e registro dos dados, o que foi realizado na instituição onde se encontram os profissionais, em local apropriado e em horário previamente agendado.

Com o propósito de abordar nas entrevistas um conteúdo que viesse ao encontro dos objetivos da pesquisa, criou-se um roteiro a ser seguido na sua realização. Dessa forma, os eixos norteadores da entrevista foram: tempo de formação e inserção no local de trabalho, experiência na instituição, dificuldades em sua prática profissional, percepção sobre o trabalho em equipes multiprofissionais e desafios encontrados dentro desse novo modelo de atenção em saúde mental.

Para dar início à análise dos dados, as entrevistas foram transcritas na íntegra, com o intuito de proceder à análise de conteúdo, que sumariamente pode ser descrita como “... um conjunto de técnicas de análise das comunicações visando a obter, por procedimentos sistemáticos e objetivos de descrição do conteúdo das mensagens, indicadores (quantitativos ou não) não permitam a inferência de conhecimentos relativos às condições de produção/recepção (variáveis inferidas) dessas mensagens" (Bardin, 1977, p.42).

As informações foram agrupadas em categorias e subcategorias, que foram relacionadas com base na semelhança entre os assuntos propostos e a frequência com que apareceram nos relatos dos profissionais entrevistados. As categorias identificadas são: (a) impacto inicial: o susto, a frustração e o despreparo acadêmico, (b) formação: (des)afiados para trabalhar em CAPS?, (c) a desinformação do psicólogo e a (inter) disciplina do trabalhador em saúde.

Os profissionais e as instituições foram identificados por uma letra, seguida de um número (para profissionais: P1, P2, ...P7; para instituições: 11, 12, 13). Dos sete profissionais que integraram o estudo, cinco deles foram formados pela universidade federal, e dois deles já com mais tempo de formação, oriundos de instituições privadas. O tempo de formação dos profissionais oscilou de 6 a 17 anos, sendo que seis dos profissionais concluíram seu curso de graduação nos últimos 10 anos quando a perspectiva da reforma psiquiátrica já se encontrava em construção no País. Cabe destacar também que, no momento da realização do estudo, todos os CAPS estavam sendo coordenados por profissionais da Psicologia.

\section{Resultados e discussão}

Os resultados serão apresentados em três categorias, as quais expressam conjuntamente as opiniões trazidas pelos profissionais que participaram do estudo. A primeira categoria concentra os aspectos que envolvem o impacto inicial vivenciado pelos profissionais, os sentimentos associados a esse momento, bem como a necessidade de reorganizar as práticas e os saberes com vistas a se adaptar ao novo contexto. A segunda aborda os aspectos relacionados à formação profissional, principalmente nos cursos de graduação, que, segundo os profissionais, possuem certas fragilidades, pois não oferecem uma formação adequada para se atuar no contexto do CAPS. Por fim, a terceira e última categoria concentra o tema da ressignificação da prática profissional, destacando a importância da pluralidade de 
olhares (multidisciplinariedade) e do trabalho em equipe.

Impacto inicial: o susto, a frustração e o despreparo acadêmico

O primeiro impacto narrado pelos participantes relaciona-se a um sentimento expresso como um susto, como ilustram os relatos que se seguem:

Foi assustador, porque a primeira vez, a primeira semana que eu vim pra cá, um paciente teve um surto, começou a quebrar os vidros. E eu pensei: 'meu Deus, o que é que eu tô fazendo aqui'! (P1)

Então, não são todos os profissionais que conseguem sair do seu eixo, todo mundo que chega aqui leva um choque. Acho que tem assim que um primeiro susto de tentar tirar o verniz, pensar no fazer junto, que é difícil assim pra todo mundo que chega aqui. (P6).

De acordo com Sales e Dimenstein, em estudo semelhante realizado com profissionais psicólogos no Rio Grande do Norte, entre as dificuldades apontadas pelos profissionais, foi citada a insegurança diante da realidade do CAPS. Tais profissionais apontam também o temor diante das crises dos pacientes. Sentimentos como medo, insegurança, dúvidas e incertezas se fizeram presentes. Pode-se pensar que tais manifestações traduzem a realidade de ver-se inserido em um local que pretende ser substitutivo a uma prática já amplamente criticada; dessa forma, parece esperado que um profissional que venha para um CAPS construa uma perspectiva inovadora e transformadora (Sales \& Dimenstein, 2009).

A narração a seguir expressa a ideia de que há necessidade de aprender muitas coisas quando se entra em um serviço dessa natureza, que implica lidar com o não saber e com a necessidade iminente de dar conta de uma demanda que espera por resultados. Iniciei, então, em (...) de 2007; tinha uma outra psicóloga aqui que tinha iniciado em (...) de 2007, então ela era nova aqui também, e eu também. Eu tive que aprender muita coisa de CAPS, porque assim, eu não sabia como é que era a forma de funcionamento dentro dum CAPS. (P2).

Por outro lado, sabe-se que uma nova proposta de novo modelo não desconstrói imediatamente o modelo anterior, que segue, como nos lembra Ferro: “... qualquer nova prática se instaura em momento histórico, e não se vê livre de seus legados" (2009, p.757). O profissional a seguir parece ter-se assustado justamente com essa dualidade entre o novo e o antigo e faz a constatação de que estar em um CAPS não significa trabalhar com um modelo novo dotado de uma prática criativa e inovadora (Sales \& Dimenstein, 2009).

(...) no momento inicial, eu me assustei um monte, porque funcionava de uma outra forma aqui o CAPS, bem ambulatorial; tu vinha aqui, não era como agora, era aquele silêncio, eram consultas bem clínicas, eram 50 minutos, muito assim tudo em torno da Psicologia e da psiquiatria, tudo passava pela avaliação psiquiátrica, avaliação psicológica (...); eu, de certa forma, não escolhi, né? Foi uma coisa 'olha, vai abrir o CAPS novo e tu vai pra lá!' (P5).

Após o impacto inicial, o susto parece ter sido substituído por sentimentos de frustração frente a alguns impasses da prática, o que pode ser visualizado por meio do relato que se segue:

(...) no início, eu acho que a frustração, eu acho que até hoje, a frustração é muito grande, porque a dependência química é muito complicada, né. A gente aposta num paciente, né. Não acredita, porque eu acho que eles realmente não mentem, mas eu acho que a gente aposta e acha que vai dar certo, dessa vez vai, e aí, quando vê, o paciente recai. Isso frustra muito. Isso antes era pior. Hoje eu ainda fico frustrada, mas no início era bem pior. (P1).

A frustração também está ligada, em grande parte, às dificuldades de ordem estrutural, especialmente no que tange à crescente 
demanda, assim como se percebe a dificuldade para superar o modelo mais amplamente difundido das práticas psi. Nesse sentido, notam-se as dificuldades e, ao mesmo tempo, as angústias dos profissionais que certamente conhecem os objetivos dos serviços substitutivos dentro do Novo Modelo de Atenção em Saúde Mental (Brasil, 2001). Como aponta Ferro, “... aos serviços substitutivos, interessa enxergar e levantar desejos dos indivíduos atendidos e possibilitar a esses a participação social em outros papéis sociais que não os reservados à doença" (2009, p. 758). O profissional abaixo traduz essa inquietação relativa à demanda, ao atendimento e às práticas inovadoras:

Pra te dar um exemplo, quando eu entrei pra cá, eu lembro que eu conversava muito com o X, não, tu entra, tu faz no máximo cinco atendimentos individuais. Em duas semanas que eu já tava aqui, eu já tinha dez. Daí, tu vai entrando e aquilo vai te sugando, e tu vai entrando naquilo, e daqui a pouco não, não tem como funcionar de outra forma, tem que funcionar desse jeito. Tu acaba entrando, e muitas vezes a gente entra no que os pais trazem, né. (P5).

Outra coisa que a gente não sabe lidar às vezes é com a quantidade de pacientes. Até é em torno de 250 pacientes. (...) Então assim, quando tu não conhece, tu tem dificuldade de dar, de ver que plano terapêutico fazer pr'aquele paciente, sabe. Até o pessoal que era dos CAPS pra reunião de equipe, assim, quando a gente não conhece muito os pacientes, a gente não sabe muito o que fazer. Então a gente tenta se aprofundar mais na história deles pra tentar fazer um bom tratamento, né, propor um bom tratamento. (P2).

Após o impacto inicial e o susto passado que se alia à frustração crescente, aparecem os primeiros movimentos de reflexão frente ao caminho desconhecido. Os participantes nos levam a pensar que passa a haver um questionamento sobre a formação (acadêmica) de cada um e o quanto ela deu conta ou não de prepará-los para atuar em um serviço de saúde dessa natureza.
(...) a gente veio assim tendo que aprender muito, né, e essa parte da psicose que a gente trabalha muito aqui também, muito pouco. Então a gente vai, assim, uma auxiliando a outra, a gente montou uns grupos de estudos, alguma coisa assim pra ir aprendendo. Então, essa dificuldade da formação... e que a prefeitura não nos possibilita capacitação. (...) Nada! Nada! Agora assim o pessoal que tá indo pra esse CAPS X que vai ter, eles tão fazendo tipo um estágio assim de... (P5).

Segundo um dos psicólogos integrantes do estudo, ele se sentia "caindo de paraquedas". Nesse sentido, Ferro adverte para o fato de que alguns profissionais podem considerar um trabalho excessivo deslocar-se das cômodas ou tradicionais ferramentas de trabalho para transpor e ampliar as possibilidades de ação da prática profissional, como afirma o profissional abaixo em relação ao sentimento de "não estarem fazendo o que elas deveriam fazer". Tal desafio coloca em questão os alicerces profissionais e a necessidade de um trabalho multiprofissional com interlocução e trocas permanentes entre a equipe. Destaca-se nesse sentido que a prática psicológica foi historicamente marcada por uma prática individual e a-histórica (Oliveira et al., 2004; Lima, 2005; Sales \& Dimenstein, 2009).

(...) todos os funcionários que entraram aqui não tiveram capacitação, inclusive nós, da Psicologia. Ninguém teve capacitação. A prefeitura simplesmente pega o profissional, chama no concurso e larga dentro do CAPS. E eu não acho certo isso, sabe. Eu já reivindiquei várias vezes capacitação, porque uma coisa que a gente não sabe fazer e daí entra nas dificuldades e da Psicologia também é compreensão, porque falam, né, é um horror a contenção física, mas às vezes é importante fazer contenção física. E como que se faz? (P2).

Fica claramente evidenciado pelos psicólogos o quanto é impactante a inserção de trabalho no CAPS, e tal aspecto é de extrema relevância considerando que há um movimento que espera superação por parte dos profissionais no sentido de que "o trabalho com a loucura nos serviços substitutivos exige uma mudança nos 
modos de agir, de cuidar, de acolher, tarefa extremamente desafiante e produtora de sofrimento e exaustão nos profissionais" (Sales \& Dimenstein, 2009, p. 820). A veemente solicitação por capacitação associada ao sentimento de ver-se jogado em um serviço não definido pode ser aqui entendida como a manifestação das angústias e das incertezas de ver-se caindo de paraquedas em um terreno movediço.

\section{Formação: (des) afiados para trabalhar em CAPs?}

Embora desde 1977 tenham ocorrido, nos cursos de Psicologia, reformas curriculares, com mudanças em diversos aspectos, como exclusão ou inclusão de disciplinas, alteração de nome de disciplinas, etc (Medeiros, 1989), autores têm apontado que os cursos ainda estão fortemente baseados no modelo clínico privado de consultório, com a tendência do profissional de generalizar esse modelo hegemônico para outras áreas e contextos de atuação, sem conseguir compreender, explicar ou sugerir alternativas para os problemas cotidianos vividos pelas pessoas (Bardagi, Bizarro, Andrade, Audibert, \& Lassance, 2008; Neto, 2008; Rutsatz \& Câmara, 2006; Dimenstein, 1998).

Essa tendência na formação foi expressa pelos entrevistados:

(...) a dificuldade maior no meu caso foi uma questão mesmo de formação, porque, na verdade, eu vim preparada pra ser uma psicóloga clínica tradicional de consultório, e aí tu vê que, depois que tu te forma, nem sempre é o que vai acontecer na tua vida. Claro que às vezes eu sou uma psicóloga clínica porque eu atendo em consultório e tudo, que são casos, digamos assim, muito mais fáceis de lidar... (P4).

Em relação a esse aspecto, Oliveira et al., em estudo realizado com psicólogos no Estado do Rio Grande do Norte, evidenciaram um forte direcionamento do currículo para a área clínica, assim como a área de estágio curricular predominante foi a clínica. Se estendermos essa realidade para o País, poderemos compreender as dificuldades relatadas pelos profissionais deste estudo, que sentem terem sido mais preparados para a prática clínica (individual) do que para atuações comunitárias. Em relação a esse aspecto, Lima chama a atenção para as dificuldades evidenciadas por profissionais em serviços de saúde pública no sentido de desenvolverem o que a autora denominou atuação psicológica coletiva. Em concordância com Oliveira et al., Lima também associa essas dificuldades à formação profissional ainda não voltada para os novos modelos de atuação em saúde no País.

O profissional abaixo expressa com clareza as questões já referidas com relação aos questionamentos quanto à formação profissional e à dificuldade de sair do lugar que the foi previamente imposto como resultado da trajetória de atuação da Psicologia ao longo de sua história. Sob esse aspecto, pode-se compreender as angústias manifestadas pelos profissionais quando dizem ser difícil sair desse modelo.

(...) na Psicologia, que eu posso te falar que me vem assim bem forte, que me incomoda digamos assim, na questão da formação dos psicólogos, né, de acharem assim, por exemplo, se eu não tiver uma sala totalmente àquela coisa clínica, então eu não tenho como trabalhar. Não tem, isso é impossível dentro de um CAPS, né. (...) Mas é bem difícil assim sair desse modelo, porque daqui a pouco, quando tu vê, tu já tá lá chamando, levando pra tua sala, já tá conversando e já tá fazendo uma consulta e já tá marcando de novo, é bem difícil. E aqui assim, a gente cai muito nisso. (P5).

(...) as pessoas vão trabalhar nos CAPS, nessa nova organização que vem pela reforma, sem ter a mínima, mesmo assim oh, mesmo, as pessoas ouviram falar o que é reforma, que a reforma é (...) desinstitucionalização, mas é só isso que se sabe, e não sabe do que se produz a partir daí, dos conceitos, 
ou os conceitos são repetidos sem ter sido problematizados. (P3).

É interessante destacar que, ao mesmo tempo em que os profissionais denunciam as amarras com relação ao modelo tradicional de formação na área clínica, sentem-se desafiados a reinventar novas práticas, uma vez que, ao verem-se inseridos em um serviço decorrente de uma reforma e que busca ser substitutivo, angústias ou inquietações dessa natureza se fazem presentes, pois há de fato uma necessidade de reorganização de novas práticas para esses novos horizontes de trabalho.

Então a gente se sente muito angustiado, se a gente continuar naquele modelo de consultório de atendimento individual que a gente ainda tá muito trabalhando, assim, aqui vai ficar cada vez mais difícil. (P6)

Essa observação, dentre outras que apareceram, nos mostram que é preciso reinventar práticas psi dentro do atual modelo de atenção em saúde mental (Nascimento, 2004; Sales \& Dimenstein, 2009). Os profissionais já não podem, e nem querem, permanecer ancorados em práticas tradicionais.

Eu acho que o desafio é justamente isso, quebrar isso pra um psicólogo dentro da sua formação, essa ideia clínica, dessa coisa como se só a clínica funcionasse, de ampliar esse olhar. (P5).

Considerando que os Centros de Atenção Psicossocial são serviços recentes no País (Brasil, 2002), é importante pontuar que, para alguns dos profissionais, esse serviço ainda não existia quando da sua formação, o que vai exigir um forte movimento em busca de práticas inovadoras que respondam às expectativas do novo modelo de saúde mental proposto para o País pela Lei da Reforma Psiquiátrica (Brasil, 2001). Destacase ainda que o contato com problemáticas voltadas para a loucura eram restritos para os psicólogos, aspecto que, como já mencionado na primeira categoria, também vai exigir uma adaptação e um envolvimento diferente.

CAPS, por exemplo, na época não existia (na época de minha formação), né? Existia ainda os hospitais psiquiátricos. (P1).

Mas, assim, formação exclusivamente pra vir trabalhar no CAPS, eu não tive, (...) tanto é que os meus estágios, meu último estágio foi até hospitalar, mas meus outros estágios assim eram todos na área clínica. (...) a minha experiência aqui no CAPS é uma experiência um tanto quanto nova, digamos, do ponto de vista de problemas psiquiátricos. (P4).

Mas não se falava tanto em CAPS (na graduação), os CAPS tavam surgindo, porque a portaria dos CAPS é de 2002, E, eu me formei em (...). Sobre isso eu não sabia nada, não sabia nem do que se tratava. Então, por um lado, se nos faltou esse conhecimento mais teórico a respeito da rede, de SUS, por outro, a gente teve uma formação muito crítica (...). Então, no início, foi bem interessante assim, desafiador, entender a rede, entender o que é CAPS, entender, $E$, todo esse atravessamento da saúde mental, da saúde coletiva. (P6).

A riqueza das observações dos profissionais deixa claro que estamos vivendo um processo de mudança, pois eles mesmos afirmam terem tido uma formação tradicional que hoje não dá conta da realidade de trabalho na qual estão inseridos e veem-se desafiados a superar esses impasses buscando novas práticas que possam atender de forma mais satisfatória à demanda e, ao mesmo tempo, às expectativas em relação à inserção do profissional de Psicologia no Novo Modelo de Atenção em Saúde Mental.

Em relação a esse aspecto, Spink (2003), Lima (2005), Sales e Dimenstein (2009) e Ferro (2009) têm problematizado a necessidade de reflexões e estudos que possam compreender as problemáticas e as dificuldades apontadas pelos profissionais e que, ao mesmo tempo, possam servir de apoio para a construção e o fortalecimento desse novo desafio à prática psicológica. 


\section{A desenformação do psicólogo e a (inter)disciplina do trabalhador em saúde}

Ao ingressar em uma nova proposta de atenção em saúde mental, o psicólogo, então, ao lado de outros profissionais, passa a integrar o novo modelo de atenção, o qual reacende novas discussões, e o nosso serviço é lidar com tais impasses da prática buscando incansavelmente a formação continuada, pois outros tipos de responsabilidade se instalam para que esses novos dispositivos possam desempenhar efetivamente seu papel (Barbosa, 2004), ou seja, o psicólogo passa por aquilo que Belisário (1992) chamou de desenformação, que é a necessidade de sairmos de uma forma para comprometer-nos com a construção de um saber. A constatação da necessidade de formação continuada e de capacitação para desenvolver trabalhos de qualidade fica evidente nos discursos dos entrevistados:

Mas a preparação para o exercício profissional, de maneira geral, ele se dá depois. (P3)

Algumas coisas eu tive, sim, que buscar coisas novas. (P1).

Assim, são muitos os desafios para “... ressignificar e integrar saberes e práticas trazidas de suas áreas de formação" (Menegon \& Coêlho, 2005, p. 164) que levam os profissionais a criar estratégias que supram as carências de formação e que potencializem as benesses advindas da graduação.

Uma das maneiras de ressignificar a prática dos psicólogos inseridos no CAPS é com o uso de ferramentas estratégicas de qualificação e de apoio às equipes que operam o cuidado em saúde mental. As supervisões clínicoinstitucionais, estimuladas e apoiadas pelo Ministério da Saúde, são estratégias de qualificação permanente, embora muitos serviços substitutivos ainda não contem com essa possibilidade. A supervisão deve ser clínico-institucional, no sentido de que a discussão dos casos clínicos deve sempre levar em conta o contexto institucional, isto é, o serviço, a rede, a gestão, a política pública. Assim, ao supervisor, cabe sustentar o diálogo ativo entre a dimensão política da clínica e a dimensão clínica da política (Brasil, 2007). Dessa forma, parte dos profissionais referese à importância da supervisão institucional para ver o que constitui dificuldade para a equipe, o que eles, como equipe, não estão conseguindo perceber no seu trabalho. Isso se torna mais visível no que se diz abaixo:

(...) a partir de uma supervisão que foi feita, no hospital $X$ funciona assim com grupos de acolhimento, tudo era aqui ao mesmo tempo sem focar no diagnóstico, sem falar, sem dar parecer pra escola, sem dar laudo, porque isso assim é um pedido bem frequente. Então, a gente não fala, a gente vai na escola e discute o caso, né... A gente sempre trabalhou com a diretriz de não se focar nisso, de poder sentar e ver o que tá havendo com essa criança, esse adolescente. (P7).

Então, o que eu acho que é uma dificuldade bem grande nos CAPS é a gente não ter supervisão clínica institucional. A gente teve um trabalho com o professor $X$, a gente teve supervisão o ano passado, mas assim, oh. Então, acho que a gente deveria ter uma formação, espaço maior de supervisão, de formação, acho que isso emperra o trabalho muitas vezes, né. (P6).

Outra estratégia de ressignificação - que também é um grande desafio - é o trabalho em equipes multiprofissionais. Sabemos que a complementação de vários saberes entre diversos campos de conhecimento proporciona o aumento da compreensão sobre os processos de doença e saúde (Menegon \& Coêlho, 2005). Sendo assim, o viés multiprofissional foi destacado pela maioria dos profissionais entrevistados.

É um trabalho multi... Inter... Acho que não tem outro jeito, né. Acho fantástico, acho que o fato não é nem multidisciplinar ou interdisciplinar. No CAPS, o caso é 
desdisciplina, né. Um pouco assim de sair dos seus guetos assim, casos assim de patologias graves a gente não dá conta sozinho, não. Uma área de conhecimento não tem como, não tem como. O ser humano é muito complexo pra gente achar que vai dar conta sozinho, assim em uma área. (P6).

(...) a gente precisa um do outro, a gente precisa fazer ponte com a escola, a gente precisa fazer ponte com todo mundo que participa da rede da vida dessa criança. Mas o trabalho interdisciplinar, acho que é uma coisa difícil, é bem difícil (...) uma linha que tu tente trabalhar com o paciente, tem profissional que tem uma linha oposta, que a gente entende que é anti, vamos dizer assim, terapêutico. E aí, como é que tu vai fazer? (P7).

Cabe destacar aqui as importantes colocações dos profissionais no sentido de demarcar as diferenças e as exigências com relação à inserção nos Centros de Atenção Psicossocial. Nesse sentido, a compreensão da necessidade de interlocução com outros profissionais é um ponto relevante, sobretudo porque, conforme ressaltamos ao longo do texto, a prática tradicional em Psicologia também foi caracterizada pelo isolamento profissional.

Uma das características que diferencia o trabalho no CAPS é porque o tratamento é concebido por esse viés da multiinterdisciplinaridade, porque existem inúmeras instituições onde o psicólogo tá inserido, mas é realizando atividades que não se comunicam, que não dialogam com outros profissionais. Então o norteador dos CAPS, a ideia da construção de um caso com a colaboração de diversos olhares. (P3).

O trabalho realizado a partir de um olhar ampliado para a perspectiva clínica é uma das possibilidades que se apresenta no processo de desenformação do psicólogo, tal como apontado a seguir:

(...) e o que é interessante no trabalho aqui não é só o trabalho clínico aqui dentro, isso é uma parte, né. Todo contato que a gente tem que ter com a rede de saúde mental, com a rede de assistência, com as escolas, né, é muito interessante e é desafiador. É bem mais difícil do que tá numa salinha fechada sozinha, né. Então são vários desafios, e aqui dentro a gente tem muitas possibilidades de invenção de trabalho; sabe, agora eu tô no acolhimento, nunca tinha estado no acolhimento, e acolhimento não é triagem, não é uma entrevista (...). Então, é atendimento individual, é atendimento em grupo, é estar no ambiente, é visita domiciliar, é visita escolar, né. Então, tem várias atividades socio-culturais que a gente faz e que são superterapêuticas. (P6).

Eu acho que o desafio é justamente isso, quebrar isso pra um psicólogo dentro da sua formação, essa ideia clínica, dessa coisa... como se só a clínica funcionasse de ampliar esse olhar. (P5).

Como se pode perceber através das explicações, vários são os desafios enfrentados pelos profissionais no cenário do atual modelo de saúde mental, e destaca-se, em especial, a importância atribuída pelos profissionais à integração com outros núcleos de formação, através de ações multi-interdisciplinares, que ampliam as possibilidades de ação para além da prática clínica estritamente individual.

\section{Conclusão}

Pode-se concluir que inúmeros são os impasses e os desafios expostos pelos profissionais, desde o susto inicial, a impotência e a frustração de ver-se diante de uma realidade que demanda mudanças, mas, ao mesmo tempo, confrontarse com práticas tradicionais, não inovadoras. O desafio entre o novo e o tradicional parece ser a marca do atual momento da prática profissional dos psicólogos nos CAPS.

Pode-se perceber no discurso de alguns profissionais a dificuldade no exercício da prática clínica dentro de um Centro de Atenção Psicossocial, uma vez que a maior parte dos entrevistados vem de uma formação mais voltada para a dimensão clínica mais tradicional; dessa forma, quando entram na prática profissional nessa modalidade de serviço, deparam-se com uma esfera mais 
ampla de trabalho, sentindo-se despreparados para a função; no entanto, estão a todo momento ressignificando e reinventando novas práticas psi, além daquelas trazidas de suas áreas de formação.

A falta de capacitação e a valorização da supervisão clínico-institucional por parte dos profissionais entrevistados merecem destaque nesse trabalho. A partir das entrevistas, observa-se que os profissionais demandam capacitação antes de entrarem no serviço de saúde mental, ou seja, carecem de uma preparação anterior para assumirem sua função na prática.

A supervisão institucional faz-se necessária devido a várias questões, e deve sempre levar em conta o conjunto institucional, ou seja, a rede, a gestão, o serviço, a política pública, as discussões dos casos clínicos; além disso, possibilita um espaço para compartilhar os sentimentos dos membros da equipe, como sujeitos inseridos em um contexto multiprofissional.

Outro aspecto observado dentro dos serviços substitutivos foi a participação efetiva dos profissionais da Psicologia, que ocupam um espaço significativo nas equipes. Destaca-se que, no momento de realização da pesquisa, todos os CAPS da cidade estavam sendo coordenados por psicólogos. 


\section{Juliana Cantele}

Psicóloga, mestranda em Psicologia na Universidade Federal de Santa Maria, Santa Maria - RS - Brasil.

E-mail: jucantele@hotmail.com

\section{Dorian Monica Arpini}

Doutora e Professora Associada do Departamento de Psicologia e do Programa de Pós-Graduação em Psicologia da Universidade Federal de Santa Maria, Santa Maria - RS - Brasil.

E-mail: monica.arpini@gmail.com

\section{Adriane Roso}

Psicóloga, Professora Adjunta do Departamento de Psicologia e do Programa de Pós-graduação em Psicologia da Universidade Federal de Santa Maria, Santa Maria - RS - Brasil.

E-mail: adrianeroso@gmail.com

Endereço para envio de correspondência:

Rua Felipe de Oliveira, no 619, apto 03, Santa Maria - RS. CEP: 97015-250

Recebido 01/04/2011, 1a Reformulação 11/09/2012, Aprovado 15/10/2012.

Barbosa, L. H. (2004). Psicologia clínica na saúde mental: uma crítica à reforma psiquiátrica. Ciências e Cognição 03, 63-65. Recuperado em 1 maio, 2009, de http://www. cienciasecognicao.org/pdf/v03/m2348.pdf.

Bardagi, M. P., Bizarro, L., Andrade, A. M. J., Audibert, A., \& Lassance, M. C. P. (2008). Avaliação da formação e trajetória profissional na perspectiva de egressos de um curso de psicologia. Psicologia: Ciência e Profissão, 28(2), 304-315. Recuperado em 11 nov., 2010, de PePSIC (Periódicos Eletrônicos em Psicologia): http://pepsic. bvsalud.org/scielo.php?script =sci_arttext\&pid $=$ S141498932008000200007\&lng=pt\&nrm =iso $>$. ISSN 14149893.
Bardin, L. (1977). Análise de conteúdo (L. A. Reto \& A. Pinheiro, trads.). Lisboa: Edições 70.

Bauer, M. W., \& Gaskell, G. (2005). Pesquisa qualitativa com texto, imagem e som: um manual prático (4a ed., P. A. Guareschi, trad.). Petrópolis, RJ: Vozes.

Belisário, M. (1992). Saúde mental: o não-lugar do psicólogo. In Psicologia: possíveis olhares, outros fazeres (pp. 91-103). Trabalho apresentado no Conselho Regional de Psicologia / 4a Região. Belo Horizonte: Rona Editora.

Brasil. (1986). Relatório da VIII Conferência Nacional de Saúde. Brasília. Recuperado em 25 jan., 2011, de http://conselho. saude.gov.br/biblioteca/Relatorios/relatorio_8.pdf. 
Brasil. (2001). Lei Federal n. 10.216. Lei da Reforma Psiquiátrica. Brasília, DF: Ministério da Saúde. Recuperado em 25 jan., 2011, de http://www.planalto.gov.br/ccivil_03/Leis/ LEIS_2001/L10216.htm.

Brasil. (2002). Portaria n. 336. Brasília, DF: Ministério da Saúde. Recuperado em 25 jan., 2011, de http://portal.saude.gov. br/portal/arquivos/pdf/Portaria\%20GM\%20336-2002.pdf.

Brasil. (2005). Ministério da Saúde. Reforma psiquiátrica e política de saúde mental no Brasil. Documento apresentado à Conferência Regional de Reforma dos Serviços de Saúde Mental: 15 anos depois de Caracas. Brasília, DF. Recuperado em 1 maio, 2009, de http://portal.saude.gov.br/portal/ arquivos/pdf/relatorio_15_anos_caracas.pdf.

Brasil. (2007). Ministério da Saúde. O ofício da supervisão e sua importância para a rede de saúde mental do SUS. Brasília, DF. Recuperado em 29 out., 2009, de http://portal.saude.gov.br/ portal/saude/visualizar_texto.cfm?idtxt=31355.

Brasil, Â. M. R. C. (2004). Considerações sobre o trabalho do psicólogo em saúde pública, Integração, 37, 181-186. Recuperado em 28 abr., 2009, deftp://ftp.usjt.br/pub/ revint/181_37.pdf.

Cunha, G. A. M. A., \& Maciel, S. C. (2008). Saúde mental - luta antimanicomial, reforma psiquiátrica e CERSAMs: campo de atuação das políticas públicas. Recuperado em 15 mar., 2009, de Web Artigos: http://www.webartigos. com/articles/11430/1/saude-mental---luta-antimanicomialreforma-psiquiatrica-e-cersams/pagina1.html.

Dimenstein, M. D. B. (1998). O psicólogo nas unidades básicas de saúde: desafios para a formação e atuação profissionais. Estudos de Psicologia, 3(1), 53-81. Recuperado em 10 jan., 2011, de http://www.scielo.br/pdf/epsic/v3n1/a04v03n1.pdf.

Fagundes, S. (2004). Apresentação. In C. A. T. Nascimento, G. D. R. Lazzarotto, J. C. D. Hoenisch, M. C. C. Silva \& R. L. Matos, Psicologia e políticas públicas: experiências em saúde pública. Porto Alegre: Conselho Regional de Psicologia, 8496. Recuperado em 20 maio, 2009, de CRP07 (Conselho Regional de Psicologia): http://www.crp07.org.br/upload/ edicao/arquivo15.pdf.

Ferro, L. F. (2009). Trabalho territorial em hospitais psiquiátricos - construindo no presente um futuro sem manicômios. Psicologia: Ciência e Profissão, 29(4), 52-67.

Goya, A. C. A., \& Rasera, E. F. (2007). A atuação do psicólogo nos serviços públicos de atenção primária à saúde em Uberlândia, MG. Horizonte Científico, 1, 01-21. Recuperado em 15 mar., 2009, de http://www.horizontecientifico.propp. ufu.br/include/getdoc. php?id $=265$ \&article $=88 \&$ mode $=$ pdf.

Kubo, O. M., \& Botomé, S. P. (2001). Formação e atuação do psicólogo para o tratamento em saúde e em organizações de atendimento à saúde. InterAÇÂO, 5, 93-122. Recuperado em 26 ago., 2009, de http://ojs.c3sl.ufpr.br/ojs2/index.php/ psicologia/article/viewFile/3319/2663.

Lima, M. (2005). Atuação psicológica coletiva: uma trajetória profissional em unidade básica de saúde. Psicologia em Estudo, 10(3), 431-440. Recuperado em 15 abr., 2009, de http://www.scielo.br/pdf/pe/v10n3/v10n3a10.pdf.

Medeiros, J.G. (1989). O currículo como objeto de pesquisa. Psicologia: Ciência e Profissão, 9(1), 24-25.

Menegon, V. M., \& Coêlho, A. E. L. (2005). A inserção da psicologia no sistema de saúde pública: uma prática possível.
Barbarói, 24 161-174. Recuperado em 26 ago., 2009, de online.unisc.br/seer/index.php/barbaroi/article/view/824/608.

Melo, D. C., \& Borges, F. G. A. (2008). O papel do psicólogo comunitário: análise de uma intervenção e propostas de atuação, Barbarói, 24, 1-7. Recuperado em 30 ago., 2009, de http://www.ic-ufu.org/anaisufu2008/PDF/SA08-20362.PDF.

Nascimento, C. A. T. (2004). Construindo processos de organização dos psicólogos em saúde pública. In C. A. T. Nascimento, G. D. R. Lazzarotto, J. C. D. Hoenisch, M. C. C. Silva \& R. L. Matos. Psicologia e Políticas Públicas: Experiências em Saúde Pública. Porto Alegre: Conselho Regional de Psicologia, 84-96. Recuperado em 20 maio, 2009, do CRP07 (Conselho Regional de Psicologia): http://www.crp07.org.br/ upload/edicao/arquivo15.pdf.

Neto, J. L. F. (2008). Psicologia e saúde mental: três momentos de uma história. Saúde em Debate, 32(78/79/80), 18-26. Recuperado em 27 ago., 2009, da PUC Minas:http://www. pucminas.br/documentos/tresmomentos.pdf?PHPSESSID $=\mathrm{e}$ 7a51ebf28f5791db6ff6c8b40636bac.

Oliveira, I. F., Dantas, C. M. B., Costa, A. L. F., Silva, F., Alverga, A. R., Carvalho, D. B., \& Yamamoto, O. H. (2004). O psicólogo nas unidades básicas de saúde: formação acadêmica e prática profissional. Interações, 17(IX), 71-89. Recuperado em 10 jan., 2011, do PePSIC (Periódicos Eletrônicos em Psicologia): http://pepsic.bvs-psi.org.br/scielo.php?script=sci_ arttext\&pid =S1413-29072004000100005\&lng=pt\&nrm $=$ iso.

Pietroluongo, A. P. da C., \& Resende, T. I. M. (2007). Visita domiciliar em saúde mental - o papel do psicólogo em questão. Psicologia: Ciência e Profissão, 27(1), 1-10. Recuperado em 30 ago., 2009, de PePSIC (Periódicos Eletrônicos em Psicologia): http://pepsic.bvs-psi.org.br/scielo.php?script=sci_ arttext\&pid $=$ S1414-98932007000100003\&lng = pt\&nrm $=$.

Rutsatz, S. N. B., \& Câmara, S.G. (2006). O psicólogo na saúde pública: trajetórias e percepções na conquista desse espaço, Alethéia, 23. Recuperado em 16 mar., 2009, de PePSIC (Periódicos Eletrônicos em Psicologia): http://pepsic. bvs-psi.org.br/scielo.php?script=sci_arttext\&pid $=$ S1413$03942006000200006 \&$ lng $=$ pt\&nrm $=$ iso.

Sales, A. L. L. de F., \& Dimenstein, M. (2009). Psicologia e modos de trabalho no contexto da reforma psiquiátrica. Psicologia: Ciência e Profissão, 29(4), 812-827.

Spink, M. J. P. (2003). Psicologia da saúde: a estruturação de um novo campo de saber. In Psicologia social e saúde: práticas, saberes e sentidos (pp. 29-39). Petrópolis, RJ: Vozes. 